\title{
Equalizing and Widening Access to Higher Education During a Pandemic: Lessons Learned from a Multi-University Perspective
}

\author{
Emlyn Dodd \\ University of Technology Sydney, Australia \\ Sonal Singh \\ University of Technology Sydney, Australia \\ Jim Micsko \\ Western Sydney University, Australia \\ Kylie Austin \\ University of Wollongong, Australia \\ Carolina Morison \\ Macquarie University, Australia \\ Stuart Upton \\ Macquarie University, Australia
}

\begin{abstract}
The COVID-19 pandemic caused a rapid and unprecedented shift of widening participation and outreach activities to online and remote delivery. The impact of this went beyond practitioners and the university sector; positive and negative implications are felt by stakeholders and the broader community. This shift online is discussed through the lens of a multi-university perspective, using four case studies from university outreach programs in one Australian state. The article provides a holistic view of the lessons learned and discoveries made, informing future program design and delivery. These programs include primary and secondary students, teachers, parents, guardians and carers, and work within a range of low socioeconomic and regional, rural and remote contexts. We argue that the fundamentally necessary shift online created a profound legacy and bears potential to increase accessibility (via diversity and scale), but, simultaneously, that care must be applied if substituting face-to-face engagement with that online. While this article primarily focuses on issues of value to practitioners, it also discusses important implications for academics, support staff, and university executive regarding the access and participation of underrepresented cohorts during times of mass change.
\end{abstract}

Keywords: Widening participation; outreach programs; access and participation; online learning; student equity.

\section{Introduction}

Widening participation and outreach (WPO) programs typically engage primary and secondary students, along with teachers, parents and carers (among other stakeholders), within school contexts or on university campuses. Online WPO bears the potential to supplement traditional face-to-face delivery and present meaningful and accessible options for equity cohorts but how exactly can this be done? There is almost no published literature regarding online WPO, with universities seeking to implement such changes left to experiment without clear guidance. This article aims to address this gap, providing an initial evidence base of real-world experiences, responses and observations to inform future practice and research. This is achieved 
through the lens of four evolving, online WPO case studies from four Australian universities. The article seeks to investigate the following research questions:

1) What aspects of WPO must remain, evolve, or be removed in the shift online?;

2) What is the evidence of impact and short-term responses from participants, staff and other stakeholders following a shift online?; and

3) Can online WPO effectively and meaningfully replace or supplement traditional delivery?

The case study approach includes four New South Wales (NSW) universities working in a variety of contexts - the University of Technology Sydney (an Australian Technology Network institution), Macquarie University and the University of Wollongong (unaffiliated institutions), and Western Sydney University (an Innovative Research University). This group of institutions provide representation of the Australian higher education sector, which has 37 public universities and much diversity. The four institutions attract different student cohorts, service different locales, and have distinct institutional profiles. They are also sufficiently close geographically to facilitate a complementary and coordinated approach to enhancing equity and educational opportunities for students, while maximizing the effectiveness of resources, including expertise and practice.

Case study methodologies allow a detailed contextual analysis of real-world contexts (Yin, 1984). The strategies used by these universities to support students from a range of underrepresented backgrounds to access higher education are discussed below.

This article contributes to the national agenda of reshaping widening participation in Australian higher education postpandemic and shares practical and tangible lessons learnt. The authors have strategic oversight, management and delivery responsibilities, including in the design, evolution, and evaluation of these programs in respective institutional contexts. Case studies were written in consultation with staff involved in the day-to-day delivery of programs.

\section{Background}

Over the past two decades, despite large increases in overall access to higher education (HE), there is still a gap between the respective levels of participation of the most affluent and the most disadvantaged students. This has implications for education policy, economic efficiency, and social justice. COVID-19 has accentuated this gap and highlighted disparities in education for equity groups in Australia, such as those with low socioeconomic status (LSES); those from non-English speaking backgrounds (NESB); and those in regional, rural, or remote areas (RRR) (Dabrowski et al. 2020). ${ }^{1}$ Indeed, it is clear that in the short-term, the COVID-19 crisis will "deepen systemic socioeconomic vulnerabilities [and] widen income and wealth gaps," with subsequent economic shocks likely to further affect vulnerable groups, particularly "migrant and unskilled workers who may not adapt to virtual-work arrangements" (Lenzen et al., 2020, p. 8).

Access to post-secondary education is one of the primary mechanisms that can be utilized to offset widening income and wealth gaps for vulnerable groups, among other benefits (OECD, 2018). Historically, numerous countries have attempted to promote and provide tertiary opportunities to a range of underrepresented cohorts (Bookallil \& Rolfe, 2016; McLachlan et al., 2013). However, in the current climate, such access is becoming more difficult to obtain. Various reports (Brown, N. et al., 2020; Clinton, 2020; Drane et al., 2020; Lamb et al., 2020; Masters et al., 2020; Rapid Research Information Forum, 2020) highlight specific disruptions caused by COVID-19, and its ensuing regulations, to the secondary school education sector, including:

1) mass school closures in Australia, affecting four million students, 800,000 of whom face additional barriers as they come from LSES communities;

2) students from LSES backgrounds who risk facing long-term educational disengagement, digital exclusion, poor technology management, and increased psychosocial challenges; and

3) disruptions that will cause a significant number of students from LSES backgrounds to be unable to complete school and attain a Year 12 certificate, meaning a reduced chance of accessing further education.

\footnotetext{
${ }^{1}$ Note that this article does not focus explicitly on other equity groups identified by the Australian Department of Education, Skills and Employment (2019), including students that have a disability, identify as indigenous, or are women in non-traditional areas. Some students from these backgrounds are expected to be organically included in the case study programs.
} 
The reality of these disruptions is already emerging more broadly, with evidence indicating that COVID-19 has affected how high school students are motivated in terms of their learning and how they envision post-school pathways (The Smith Family, 2020).

In the past, many reasons have been used to justify the introduction of WPO programs, including social justice, inclusion, equity, national competitiveness, innovation, or filling the skills gap (Bradley et al., 2008). Research suggests that educational institutions must also implement and expand equity measures that increase access for students from underrepresented backgrounds (Behrendt et al., 2012; Li \& Dockery, 2015; Naylor \& Mifsud, 2019; Schwartz, 2004). It is clear that, in the present context, targeted WPO and the associated equity entry pathways to HE are more important than ever, playing a crucial role in preparing and supporting disadvantaged students for future education while also fostering continued engagement with, and completion of, high school studies in a period of upheaval and disruption.

The ability to balance and integrate the views of various stakeholders remains vital to both the success and appropriateness of online WPO in this new and unfamiliar form. Similarly, understanding the vastly different contexts in which schools operate and to which they belong remains central to the successful development and delivery of online WPO. As practitioners and researchers, we have observed significant change in what is expected of school teachers since the emergence of COVID-19. Teachers' workload has evolved and increased, shifting entire programs and curricula online and mitigating often-waning student engagement, which naturally and understandably impacts their ability to engage with WPO. This circles back to the core humanistic element of the shift online, illuminated by Vagelos (2020) and Rainford (2020), and the importance of practitioner and researcher awareness and empathy.

Traditionally, this humanistic element is fundamental to the theory and method of WPO, but it is more acutely important in the time of a pandemic and great change. This is applicable not only to the diverse cohorts of participants, but also to the multiplicity of practitioners, their teams, and stakeholders involved (see Rainford, 2020). For example, current university students are often employed to act as ambassadors or mentors within WPO programs. Their re-training, development, and employment, while bringing financial gain at times, can also lead to significant impacts and stressors when combined with their study, work, and other commitments. The challenging and unfamiliar situations brought about by COVID-19 call for exceptional awareness of wellbeing and support for both program participants and staff.

The importance of engaging parents, guardians, and carers - often described anecdotally as problematic and unachievable by WPO practitioners - increases in an environment where students are engaging with schoolwork and WPO activities from home. Bower and Griffin (2011) note that "traditional definitions of parental involvement require investments of time and money from parents, and those who may not be able to provide these resources are deemed uninvolved" (p. 78). This narrow perspective of parental engagement has serious consequences when developing meaningful parental engagement programs. Indeed, an optimal level of parent participation does not simply occur - it must be initiated and nurtured by universities. The already-uncertain and evolving future of work, accentuated by the impact of COVID-19, necessitates the importance of providing information and resources to parents so that they can effectively support their children's education and broaden their awareness of various career and future learning pathways (Fischer et al., 2019).

The impact of a global pandemic thus places practitioners and researchers in a precarious situation - one characterized by rapid programmatic evolution, the juggling of distinct and dynamic stakeholder experiences, and the inability to refer to or rely upon a precise evidentiary base of prior experience and knowledge. Though they vary by context, the challenges encountered so far by teams re-designing and delivering online WPO programs seem to be relatively similar, even on an international scale (e.g., for the UK, see Rainford, 2020). COVID-19 has accentuated the ubiquitous digital divide, with stark differences in digital access playing an important role in media commentary on educational inequity and tertiary opportunity throughout the pandemic. Such a divide is an aspect profoundly felt by teams designing and delivering online WPO, evidenced as a common feature across the case studies below. Even when barriers to digital access are overcome, regular online engagement fluctuates among various programs and contexts. Feelings of uncertainty and distance are common among participants with relatively little experience of online learning, and a lack of motivating face-to-face contact can cause disengagement. Not only is there greater distance from participants, but also between participants, thus presenting challenges when collaboration and peer interaction are crucial in the preparation, transition, and success of underrepresented cohorts (Stone, 2017). 
Ensuring that WPO participants do not fall into traps like those experienced by online tertiary education cohorts is also a key consideration in the shift of these programs. There are typically high proportions of students from equity backgrounds in online HE courses, but also much lower retention and completion rates (Stone, 2017). While such high enrollment makes it clear that online learning has an important place in widening access to university and the engagement of underrepresented cohorts, Stone's (2017) national guidelines on improving student success highlight the requisite improvements necessary to ensure appropriate support for such diverse cohorts to help them succeed in the online environment. Indeed, access without support is not opportunity (Engstrom \& Tinto, 2008). However, when enacted appropriately, meaningfully and successfully, research indicates that online engagement can transcend "geographical, physical, visual and temporal barriers to accessing education and reduce socio-physical discrimination" (Knightley, 2007, p. 281). In order to do this, online education, and by extension online WPO, needs to be conducted as a thoughtful and strategic initiative, not an "add-on" activity (Stone, 2017, p. 55). It remains clear that online and remote WPO can significantly broaden access and engagement, offering an alternative where barriers impede face-to-face participation, but it also comes with changes and compromises that require careful consideration.

\section{Case Study 1: U@Uni Academy (University of Technology Sydney [UTS])}

\section{Program Context and Aims}

Focusing on students from LSES backgrounds and commencing in Year 10, the U@Uni Academy fuses elements of WPO, alternative entry and enabling programs. It is offered to students not on track for entry into this university via ATAR, but who have nonetheless demonstrated the potential to succeed through selected criteria, $21^{\text {st }}$ century skills and achievements. This program continues to support students once they have arrived at university and therefore combines secondary and postsecondary interventions (see Simson et al., 2012). Besides building academic literacies, social capital, and navigational capital, it also utilizes future-focused assessment and tracking tailored to the experiences of underrepresented cohorts. The program directly addresses and works in tandem with recommendations made in the recent national Looking to the Future review (Shergold et al., 2020). Participants, staff and stakeholders are evaluated through surveys, focus groups, informal verbal feedback and stories of change. The pilot program was initiated in 2019 and has now expanded to 23 partner high schools in southwestern and western Sydney, with over 600 participating students. Those who successfully complete the program and meet graduation requirements are directly offered an undergraduate position at this university. ${ }^{2}$

\section{Adaptations due to COVID-19}

Since this program usually prioritizes face-to-face engagement, the unexpected changes caused by COVID-19, along with programmatic attendance requirements, necessitated a rapid re-design of all program activities. Vital to this redesign was the aspirational objective to ensure that online students were active participants and not passive consumers (Rainford, 2020).

An online module was created utilizing the existing university e-learning platform, Canvas, to maintain engagement, track and assess student capabilities, and continue the development of academic literacies and capital-building processes. This allowed the strengths of the online learning environment to be harnessed and encouraged students to appreciate how connection, collaboration, communication, and curiosity help us to share discoveries and feelings about being human. A combination of videos, quizzes, and immersive activities were used to respond to a series of prompts. Discussion boards were embedded throughout the module and moderated daily by current university student ambassadors, supplemented by Q\&As on social media channels. This encouraged help-seeking behavior, a crucial trait for online learning, facilitating a successful transition to university (Stone, 2017). It also attempted to reduce the burden on families, who were sometimes expected to assist their children's remote learning (The Smith Family, 2020).

Program managers worked closely with school contacts to transition to flexible online mentoring via Zoom. Content translated smoothly online, and two sessions led by student ambassadors focused on strategic goal setting, hope-mapping, university FAQs, and a revision of program achievements and progress to date. The sessions also allowed the opportunity to introduce participants to online learning, ensure that they can access the module, and answer questions.

\footnotetext{
${ }^{2}$ Complete program details, including attendance and graduation requirements, are located on the website: $\underline{\text { https://uatuni.uts.edu.au }}$ See also Dodd et al. (2020) for discussion of the program, its methodology, theory and context.
} 
The delivery of Higher School Certificate (HSC) tutorial sessions by ambassadors was shifted entirely online. Chat-based areas were set up within Microsoft Teams or Google Classroom, where students could receive both synchronous and asynchronous academic support.

A pilot parent engagement stream intended for face-to-face delivery was also shifted online. ${ }^{3}$ Two 'Careers Breakfast' sessions for parents and carers at partner schools were led by parent ambassadors - parents of current student ambassadors from equity backgrounds. Parent ambassadors shared career stories in a dialogue with parents, students, alumni, and teachers. The aims of the sessions were to:

1) help broaden educational and occupational aspirations;

2) increase understanding of the diverse pathways to tertiary education; and

3) raise awareness of education and training opportunities.

\section{Successes, Challenges, and Lessons Learned}

One challenge was access to appropriate devices and data for participants. Program managers worked closely with schools to supplement the NSW Department of Education (DET) assistance, providing participants with 110 laptops or tablets as well as data packages.

Comparative engagement across online components revealed a stark dichotomy. Zoom mentoring and the online module were largely successful, with high engagement and positive learning outcomes. Online HSC tutoring, however, resulted in low attendance and relatively little student engagement. In 2020, it had no compulsory attendance requirement, which, combined with existing barriers to online engagement, likely compounded this problem. Nonetheless, it is clear that more targeted cohorts and 'higher stakes' program components led to increased engagement.

Online mentoring sessions were ranked highly in post-session surveys. Ninety-three percent $(93 \%)$ of students (total $=83)$, and $95 \%$ of students agreed that the mentoring sessions had helped teach them about university life. Student comments indicated the importance of online settings that enable informed, colloquial conversations about post-secondary pathways. Motivation to pursue HE was strengthened, with $87 \%$ of students indicating that the U@Uni Academy encouraged them to go to university. Students still indicated a desire to "come onto campus" and requested "more activities" during mentoring. Certain obstacles meant that mentoring often occurred in larger groups than desired, but positive feedback indicates that perhaps group size did not affect outcomes.

The creation of individualized digital spaces seems to have increased participation of some learners. ${ }^{4}$ Students usually quiet during on-campus activities showed more engagement online. Similarly, students not attending school accessed online mentoring from home. This provided insight into the learning journey of students normally more difficult to reach and indicated that a blended approach may broaden WPO participation in a meaningful way.

The administrative load of organizing access to school-based online platforms was also a challenge. Synchronous sessions were arranged according to teacher availability, to supervise online activity. Most ambassadors reported that "really low engagement" was challenging, with sessions feeling like "one-way tutoring," though this was often due to the limitations of chat-based engagement and student unfamiliarity with Microsoft Teams. The ability to easily upload and link to resources was a common positive thread, as well as informal methods such as the use of GIFs and empathetic language to enhance communication. Ambassadors also began to innovate and create solutions independently, with one creating "a Google survey to assess [student] needs and understand the $[\mathrm{m}]$ as they came".

\footnotetext{
${ }^{3}$ This component aims to assist parents from LSES backgrounds to support their children's HE and career aspirations. The program uses best practice principles and the NCSEHE Guide for Partnerships, embedding the principles within existing WPO activities at this University.

${ }^{4}$ In a similar manner, The Smith Family (2020) found that a shift to video conferencing for community support and counselling empowered some normally disengaged individuals to seek support.
} 
Parent engagement presented methodological and ethical dilemmas in accessing potential participants to attend Zoom sessions. Common challenges, like needing both verbal and written consent, become more complex when the program involves working with parents from diverse backgrounds. However, the opportunities afforded by this approach outweigh the ethical and methodological difficulties. Post-session surveys, designed to gather data for program improvement and parent knowledge and aspiration towards HE, indicate that all participants (100\%) found the information useful and the sessions interactive, due to the involvement of parent ambassadors and all participants (100\%) reported increased confidence in supporting their child with career and study choices. In the same survey, qualitative feedback from participants highlighted the need for more information, preferably delivered by parent ambassadors. Besides broadening the educational and occupational aspirations of parents and carers, the program has evolved to build ongoing advocacy, parent empowerment, and community engagement in South-West Sydney.

\section{Case Study 2: Fast Forward School Engagement Program (Western Sydney University [WSU])}

\section{Program Context and Aims}

Fast Forward was initiated in 2004 and engages Western Sydney high school students from LSES backgrounds in Years 9-12. The program presents increasing opportunities for students to create academic and personal achievements, while preparing for post-school studies and future careers. It also enhances students' confidence and skills and provides information regarding career pathways. Practitioners and student ambassadors promote the benefits of lifelong learning and foster connections with students distanced from HE aspirations. Students are targeted in Year 9, before they arrive at key academic crossroads, such as making decisions about their educational and career paths. Currently, the program works with 85 high schools and more than 6000 students.

The program traditionally operates within high schools and on campus. Core activities include:

1) one-to-one consultations for Years 11 and 12;

2) group presentations on scholarships, early entry and adjustment factor schemes, academic support, and pathway information; and

3) events for Years 9-11, parents' information evenings, HSC study sessions, and a Year 12 conference.

The program is evaluated through student, stakeholder, and staff surveys via Qualtrics and MS Forms as well as high school teacher focus groups and informal qualitative feedback.

\section{Adaptations due to COVID-19}

Engagement ceased immediately upon implementation of the social distancing regulation. It was clear that partner schools were focused on their own responses to this new form of education. WPO staff focused on adapting and evolving program elements for continued delivery via new and existing online platforms. Communication with teachers showed issues with digital engagement, making regular and sensitive communication crucial, as well as awareness of the impacts on teacher workloads. Teacher feedback was sought with new evaluative surveys focused on comprehending the shift to online learning. This program re-design was supplemented by participant data from online analytics, illustrating school engagement with social media channels. Proactive outreach, new delivery modes, and adapted content were often necessary and added value by expanding existing offerings.

\section{Successes, Challenges, and Lessons Learned}

The shift online increased the opportunities to expand WPO in a resource-efficient manner and service new cohorts, including RRR, schools currently on a waiting list, and Years 7 - 8 students. There have also been opportunities to: 
1) increase investment in and capacity of student ambassadors from underrepresented backgrounds, thus enhancing potential capital conveyance, supporting delivery of online content, and providing tangible benefits and professional skill-development;

2) provide a tailored, guided online educational journey and ease participants' shift to HE by embedding digital learning platforms as part of the University's Employability Strategy; and

3) offer opportunities to gain future-focused skills and knowledge micro-credentials via online components, thus giving students an edge when applying to university and future work.

Initial evaluation of delivery method options via newly implemented Qualtrics surveys showed schools' widespread and conflicting preferences. Events held during school hours sometimes worked best, but others preferred options accessible ondemand or outside school hours. Thus, program design occurred in a tailored way, and on a school-by-school basis, further highlighting the different contexts that teachers must navigate to enable students to access online activities. Fast Forward staff worked via an iterative approach, testing strategies and evolving program elements. Consultations with teachers and parents fostered the discovery of appropriate and effective ways to ensure that program benefits were maintained and obstacles were avoided. This reinforced the importance of preemptive, ongoing, in-depth co-design with teachers to respond effectively to school needs.

Two webinars with flexible attendance options about Higher Education Pathways (Plan ABC) attracted approximately 400 Years 11- 12 students from 17 high schools. Following the webinars, 83\% of students reported 'very high' levels of confidence in planning their futures, an increase of over $30 \%$ from similar previous events.

The shift online enhanced staff design-thinking, technical skills, and ability to quickly innovate while working closely with stakeholders. The flexibility of online delivery increased participants' exposure to more diverse WPO staff, who they might not typically encounter.

\section{Case Study 3: Year 12 University Preparation Program (University of Wollongong [UOW])}

\section{Program Context and Aims}

The Year 12 University Preparation Program (UPP) began in 2014. It is part of an institution-wide approach to student equity commencing with Year 12 high school students and continuing to university completion. The UPP traditionally runs over a 20-week period. Before COVID-19, it engaged students via tutoring in HSC subjects, providing study skills and mentoring for successful post-school transitions. The objectives of the Program have been to:

1) build the academic capacity of students by enhancing their knowledge in subject areas relevant to their HSC studies and post-school goals;

2) enable students' aspirations through impactful career advice and pathways planning; and

3) develop students' skills for a successful transition to a post-school educational environment.

The program usually engages with students in high schools across six regions. ${ }^{5}$ Aligned with the Bradley Review of Australian higher education, the UPP targets students from LSES backgrounds, students with disabilities, Aboriginal and/or Torres Strait Islander students, and RRR students who aspire to further education or employment but are not academically on track at the end of Year 11 (Bradley et al., 2008; Koshy, 2018). Student attendance data is taken and short surveys, in the form of 'pulse checks' to measure engagement, are completed each week.

The strength of the UPP derives from its place-based approach, which entails engaging with students and providing content relevant to their regional or metropolitan contexts. In each region, the program is led by local outreach coordinators with long-

\footnotetext{
${ }^{5}$ Batemans Bay, Bega, Shoalhaven, Southern Highlands, southwestern Sydney, and Wollongong regions.
} 
standing relationships with the communities. Each coordinator employs a team of casual outreach mentors who are current university students, including some who have attended partnered high schools. The main principle of the program allows it to be designed and delivered in ways that meet the needs of a diverse regional student cohort.

\section{Adaptations due to COVID-19}

The impact of COVID-19 resulted in a shift to a remote learning model within four weeks. This required a complete redesign guided by Stone's (2017) National Guidelines. The broader widening participation context necessitated the implementation of new design considerations, including a structured approach to school and parental engagement, maintaining the commitment to WPO in an increasingly pressurized environment, building familiarity and connection to HE even through a remote learning environment, and maintaining a place-based approach to ensure that content was tailored to the needs of students in different regions.

Indeed, a place-based approach is a major consideration in the shift to remote delivery (Bartholomaeus, 2006). A working group was established to ensure that both regional and metropolitan lenses were embedded in the design from the outset. Continued program delivery by regional mentors and alumni of the same high school was critical for student engagement (Austin \& Hatt, 2005). Key topic areas were adapted based on specific learning needs, resource requirements, and preferences, while also considering the complexities within the wider rural school environment (Brown, B. et al., 2020; Devlin \& MacKay, 2017; Penman, 2010).

\section{Successes, Challenges, and Lessons Learned}

In 2020, remote delivery of the UPP engaged with 574 students across 63 high schools, and thus reach was expanded to include RRR students that were previously unable to engage face-to-face. ${ }^{6}$ There was also a $7 \%$ increase in participants from the Bega, Batemans Bay, Shoalhaven, and Southern Highlands regions.

Student retention and engagement also increased compared to previous years. Mid-way through program delivery, the retention rate sits at $97 \%$ ( $80 \%$ of students typically complete the program annually). Engagement in the program is more transparent than before, with students rating weekly sessions positively in terms of relevance and engaging content. Student feedback is actively used to reshape and refine the weekly content to maintain relevance.

During the initial weeks of program delivery, the key lessons learned were as follows:

1) facilitating student interaction in online environments must be undertaken in ways that build student confidence;

2) there should be active outreach to ensure students are proficient in online platforms;

3) schools and families need regular communication during program delivery, so all three key influencers send a consistent message; and

4) the shift online has an impact on WPO staff workload and wellbeing, as they learn new skills and delivery methods while shifting online.

\footnotetext{
${ }^{6}$ These included students from the Monaro, Riverina, Central West, and Tamworth regions.
} 


\section{Case Study 4: LEAP ROADShow and inROADS Regional Outreach (Macquarie University)}

\section{Program Context and Aims}

The LEAP school engagement program is a suite of complementary outreach initiatives connecting RRR students and members of their communities to information about learning, educational, and career opportunities. ${ }^{7}$ LEAP ROADShow combines university, a network of academics, and current students to engage RRR Years 5-10 students in their communities. LEAP inROADS continues this journey for Years 11-12 students, offering them a stay on campus to give them a sense of familiarity, contextualization, and the possibility of future learning. These initiatives were designed to establish 'warm' connections with RRR students, educators, and their communities to share reliable information, knowledge, and guidance and enhance students' decision-making in relation to HE. ${ }^{8}$

Building connections with RRR communities is intended to not only empower communities to become active within an HE network, but also to enhance students' awareness of diverse educational opportunities; confidence to consider and pursue HE; ability to relate to $\mathrm{HE}$ as a relevant and beneficial pathway; and awareness of support (e.g., financial, academic, and wellbeing) available at university to aid their transition to HE. Program data is collected and evaluated using a mixed methodology, including paper-based and online survey, TurnPoint software, focus groups, and experiential feedback from stakeholders (students, teachers, community members and collaborators).

\section{Adaptations due to COVID-19}

The effects of COVID-19 prompted a redesign of initiatives. Broadening the network of partnerships while maintaining connections online was crucial in supporting RRR students and their communities. A series of responsive initiatives was also put in place, including:

1) invitations for school communities to participate in inclusive, online, student-focused conferences creating a meaningful two-way exchange of information between participants and university representatives;

2) delivery of informal weekly online conversations between university and high school students to ease anxiety surrounding post-school expectations; and

3) access to online lessons for students and educators to support HSC learning in the sciences.

These measures were designed following the research findings of Stone (2017), which noted the need for online initiatives providing early intervention to connect, prepare, and provide realistic expectations and academic preparation; regular structured contact with the institution; and institution-wide collaboration to integrate and embed support, delivering it to students at the point of need.

\section{Successes, Challenges, and Lessons Learned}

Online initiatives offer a viable and effective avenue for HE providers to maintain engagement with RRR students and their communities. They supplement in-person initiatives that enable RRR students to access educational information, options, and opportunities. They do not, however, substitute for the positive impact of in-person initiatives, including relationships or experiences.

Experiences with LEAP ROADShow and inROADS highlighted that online WPO can be incorporated into school environments and timeframes with minimal disruption. Students and educators can flexibly participate and interact. This provided a valuable space for students, encouraging them to participate with higher levels of curiosity and inquiry than during

\footnotetext{
7 The Independent Review into Regional, Rural and Remote Education identified that the underrepresentation of students from RRR backgrounds in HE correlated with under-subscribed application rates - the likely result of needing "access to and then being able to effectively use a suite of resources that turn aspirations and interests into reality" (Halsey, 2018, p. 22).

${ }^{8}$ Slack et al. (2014) describe warm sources of information as agents who have the capacity to supplement, affirm, or negate socially sourced 'hot' or institutionally acquired 'cold' information.
} 
face-to-face initiatives. Over time, shorter, less intensive, but more regular information sessions, conferences, and conversations were effective. This allowed students to absorb, reflect, and engage with the content and information, while continuing to build rapport with university representatives - important aspects to show that WPO practitioners and representatives are committed to enabling positive outcomes for RRR communities and students. The variability of individual or regional access to information and communications technology services and resources was an obstacle. Online initiatives sometimes had technological disruptions, prompting delays in delivery. The complexity of connectivity for RRR communities is a known barrier and priority recognized as important to ensure RRR students' access to future educational and career opportunities.

\section{Discussion}

Before addressing the challenges posed by a pandemic and the changes to WPO design and implementation required, it is important to note that, as the case studies illuminate, many best practice aspects of traditional face-to-face WPO remain relevant. This directly addresses the initial component of research question 1: What aspects of WPO must remain in the shift online?

It remains vital, for example, to encourage collaboration and break down barriers between academic and professional staff in order to deliver holistic online student experiences with appropriate co-design and support mechanisms, as well as avoiding repeated failures when lessons can be shared (Rainford, 2020; Stone, 2017). It is equally important to aspire to whole of university approaches, where WPO activities are not exclusively owned by equity departments, but involve collaboration, codesign, support and buy-in from faculties, executive and professional areas of staff. Broader than this, cross-institutional collaboration and co-design should be encouraged wherever possible; the effective execution of which is highlighted across the case studies.

Programs should preserve the importance of authentically conveying different forms of capital, whether social, navigational, bridging, or bonding (Chesters et al., 2018; O’Sullivan et al., 2019); promoting mentorship (Cotton et al., 2013; Dodd et al., 2020); and developing academic literacies (Christie et al., 2013; Irwin et al., 2018). The integration and prioritization of mentoring and capital-building program elements in all case studies is a testament to this. Furthermore, WPO should not be satisfied with the sole methodology of increasing the awareness and aspirations of underrepresented students, but must maintain the recent trajectory of expanding equity measures and forming distinct and appropriate entry pathways for these cohorts (Dodd et al., 2020). ${ }^{9}$ Finally, programs should be guided by overarching student-centric and strength-based approaches, with opportunities for the acknowledgment of student voices and the sharing of stories (Lawrence, 2004).

However, the impact of a global pandemic and the restrictions that follow necessitate a vast and rapid programmatic evolution, as seen at these four universities. Regardless of the knowledge that many methodological WPO elements remain relevant, it must first be acknowledged that the delivery, scope and perspective of programs require change. Thus, we turn to the latter component of research question 1 - what aspects must evolve or be removed. Rainford (2020) suggests three distinct dimensions, consonant with the literature on e-learning, that must be considered when shifting WPO online: the pedagogy, technology, and humanistic dimensions. While these are useful considerations, such broad-stroke categories often fail to illuminate the reality of practice, particularly in the increasingly unpredictable pressure-cooker environment experienced by WPO professionals throughout the COVID-19 pandemic.

Online programs, by nature, often run on timelines different from traditional WPO activities, with extended hours and activities available asynchronously to participants when desired. Case studies highlighted programmatic evolutions required and the importance of balance between synchronous and asynchronous activities, particularly when synchronous activities can be heavily biased in favor of certain participants at the expense of others (Bali and Meier, 2014; Stone, 2017).

Varied delivery methods and timeframes also caused a change in the tempo of WPO practice in terms of program design, implementation, and communication. The importance of personalized contact for online cohorts, whether through telephone or appropriately regulated face-to-face components, is well-known (Stone, 2017). Similarly, teacher-student engagement,

\footnotetext{
${ }^{9}$ O'Sullivan et al. (2019, p. 556) suggest that a focus on the traditional "aspiration strand" of WPO does little to address societal and structural barriers that limit progression and might even reinforce cultural and socioeconomic divisions based on a deficit model.
} 
where it is important in traditional contexts, becomes even more crucial in the online space. Here, evidence from the case studies also begins to speak to research question 2, regarding impacts and short-term responses. Teacher presence, through positive and constructive communication - whether by practitioner, ambassador, or mentor - formed a key component across the case studies and positively impacted sense of belonging in the online community. In longer-term studies it is also known to improve retention (see Stone, 2017). This builds a sense of connection with the institution as a whole, which assists the process of transition.

As with tertiary online education (see Stone, 2017), it became clear that WPO programs designed for face-to-face delivery could not be forced into an online ecosystem. This in itself created challenges. Those programs that integrated online modules and activities often effectively and meaningfully supplemented the creation of new content with curation of existing content. Leveraging and curating content from external organizations, often with increased capacity and resources compared to WPO teams, can, in fact, enable a better online participation experience (Rainford, 2020).

Lack of time in a rapidly evolving system of regulations was felt throughout the case studies and continues to provide evidence of impacts to and responses by stakeholders (research question 2). Practitioners, for example, contended with the stress of balancing thorough and considered development of online programs to ensure that they were appropriately created and studentfocused versus the ever-increasing need to quickly engage with underrepresented cohorts, avoiding disengagement or disconnection. The importance of rapid pivots and continual engagement, maintaining connection and belonging, was vital for cohorts within the case studies - particularly, in an increasingly competitive national higher education climate.

Practitioner responses led to realignment of practice to manage expectations and their own health, while ensuring that participants still received support. Some program managers used 'pulse checks' to regularly check in on participants and staff via simple surveys. This allowed them to quickly respond and adapt to needs as they arise. It is also vital to manage the expectations of participants, many of whom may only have engaged with traditional WPO and have little or no background in online education, let alone remote WPO. Here, honesty and transparency played a critical role regarding changes to program structures, activities, dates, and experiences ahead (see Stone, 2017). Such evolutions and responses, with embedded impacts, clearly illuminate that research questions 1 and 2 are intimately (and causally) linked, with evidence and conclusions from case studies applying to both simultaneously.

A number of case studies utilized university e-learning platforms (Learning Management Systems) to deliver online modules, which provided participants with an enhanced introduction to university study typically not offered by WPO. This inadvertently increases the ability and preparedness of participants to transition to HE, as well as their sense of belonging in the tertiary ecosystem. Furthermore, many of the skills involved in navigating these spaces are considered important life skills (e.g., file storage and time management). Online engagement also often improved the digital literacy and capability of participants and encouraged independent learning - an investment in skills vital for retention when students reach university (Rainford, 2020). It is clear that there are distinctly positive impacts achieved through online WPO, not typically possible via traditional delivery, and that these should continue in some form to influence program design and delivery.

Stakeholder consultation, as well as existing research, revealed the concern among teachers and families that students will fall behind at school when learning from home (The Smith Family, 2020). When expectations of WPO participation are layered onto this, real concern for student wellbeing emerges. Not only does this speak to research question 2 , but also 3 , when considering whether online WPO can effectively and meaningfully replace or supplement traditional delivery. Case studies often addressed this through proactive outreach, sensitive and empathetic stakeholder communication, and regular feedback via checkpoints or milestones.

Student evaluation and qualitative feedback across several online components acknowledged a generally positive experience with online engagement but also a clear and consistent desire to return to face-to-face or on-campus WPO. This was regularly expressed in terms of missing hands-on activities in faculty-specific spaces. When frequent positive sentiment towards making new friends and connecting with other students in person is added to this from past on-campus activities, it is possible to suggest that online WPO, while valuable in certain respects, cannot wholly nor meaningfully replace traditional face-to-face delivery. It is clearly important, therefore, to be realistic and acknowledge evolving possibilities and expectations (Hodges et al., 2020). 


\section{Conclusion}

The voices represented within this article- those of practitioners, students, teachers, parents, and researchers - highlight the sharp changes to practice and experience caused by COVID-19. At its core, the flexibility of stakeholders ensured continual delivery of programs across all sectors. Evidence drawn directly from the four case studies, along with themes raised in the ensuing discussion, illuminates a series of overarching conclusions keyed to the research questions:

- The rapid and unprecedented shift of WPO to the online and remote space is a profound change in practice and new experience for all stakeholders with a lasting legacy;

- Such a rapid shift to ensure continual program delivery is fundamentally vital in the current national and global higher education and access climate;

- The implementation of online components can engage diverse, new cohorts, increase the scale of engagement, and provide participants with exposure to a greater range of WPO and learning experiences than traditionally encountered; and

- Online WPO is a valuable supplement to traditional face-to-face engagement with potential for positive stakeholder impact and diverse learning opportunities, but careful and balanced consideration must be applied if intending to substitute one for the other.

Providing a foundation for these conclusions, and as highlighted by Vagelos (2020), is the knowledge that awareness and empathy checks must be embedded throughout online WPO programs and humanistic elements foregrounded.

These conclusions provide, for the first time, an evidence base to inform future online WPO program design and delivery in a variety of contexts and with a range of stakeholders. As students return to school and we settle into a 'new normal,' the challenges will, undoubtedly, shift. How will these programs continue, evolve, or pivot once more? Many WPO programs look to embed newly designed online components into more traditional face-to-face frameworks, while others utilize digital options as backups or supplementary offerings to increase contextual accessibility. Regardless of the path taken, it is clear that, while challenging and overwhelming at times, the COVID-19 pandemic has invigorated, expanded, and created new and exciting future-focused WPO models. 


\section{References}

Austin, M., \& Hatt, S. (2005). The messengers are the message: A study of the effects of employing higher education student ambassadors to work with school students. Widening Participation and Lifelong Learning, 7(1), 1-8.

Bali, M., \& Meier, B. (2014). An affinity for asynchronous learning. Hybrid Pedagogy. https://hybridpedagogy.org/affinityasynchronous-learning/

Bartholomaeus, P. (2006). Some rural examples of place-based education. International Education Journal, 7(4), $480-489$.

Behrendt L., Larkin, S., Griew, R., \& Kelly, P. (2012). Review of higher education access and outcomes for Aboriginal and Torres Strait Islander people. Department of Education, Skills and Employment. https://www.dese.gov.au/aboriginaland-torres-strait-islander-higher-education/review-higher-education-access-and-outcomes-aboriginal-and-torres-straitislander-people

Bookallil, C., \& Rolfe, J. (2016). Counting the cost of second-chance education: Evaluating the outcomes and costs of university-based enabling programs. Widening Participation and Lifelong Learning, 18(2), 5-21. https://doi.org/10.5456/WPLL.18.2.5

Bower H. A., \& Griffin, D. (2011). Can the Epstein model of parental involvement work in a high-minority, high-poverty elementary school? A case study. Professional School Counseling, 15(2), 77-87. https://doi.org/10.1177\%2F2156759X1101500201

Bradley, D., Noonan, P., Nugent, H., \& Scales, B. (2008). Review of Australian higher education: Final report. Department of Education, Employment and Workplace Relations. http://www.voced.edu.au/content/ngv\%3A32134

Brown, B., Avitaia, S., Austin, K., \& Facchin, J. (2020). "Having a yarn": From one rural student to another, practical inschool programs demystifying university and enabling student progression. Australian and International Journal of Rural Education, 30(1), 18-32. https://journal.spera.asn.au/index.php/AIJRE/index

Brown, N., Te Riele, K., Shelley, B., Woodroffe, J. (2020). Learning at home during COVID-19: Effects on vulnerable young Australians. Independent Rapid Response Report. University of Tasmania. https://www.utas.edu.au/_data/assets/pdf file/0008/1324268/Learning-at-home-during-COVID-19-updated.pdf

Chesters, J., Rutter, K., Nelson, K., \& Watson, L. (2018). Alternative pathways into university: Are tertiary preparation programs a viable option? Australian Universities' Review, 60, 35-44. https://www.nteu.org.au/article/Alternativepathways-into-university\%3A-Are-tertiary-preparation-programs-a-viable-option\%3F-\%28AUR-60-01\%29-20306

Christie, H., Barron, P., \& D’Annunzio-Green, N. (2013). Direct entrants in transition: Becoming independent learners. Studies in Higher Education, 38(4), 623-637. https://doi.org/10.1080/03075079.2011.588326

Clinton, J. (2020). Supporting vulnerable children in the face of a pandemic. University of Melbourne. https://apo.org.au/node/303563

Cotton, D., Kneale, P., \& Nash, T. (2013). Horizon scanning report: Widening participation, retention and success. Plymouth University. https://www.plymouth.ac.uk/uploads/production/document/path/1/1672/PedRIO_Paper_1.pdf

Dabrowski, A., Nietschke, Y., Taylor-Guy, P., \& Chase, A-M. (2020). Mitigating the impacts of COVID-19: Lessons from Australia in remote education. Australian Council for Educational Research. https://doi.org/10.37517/978-1-74286-618$\underline{5}$

Department of Education, Skills and Employment. (2019). National Regional, Rural and Remote Tertiary Education Strategy. Final Report. Commonwealth of Australia. https://www.dese.gov.au/access-andparticipation/resources/national-regional-rural-and-remote-tertiary-education-strategy-final-report

Devlin, M., \& McKay, J. (2017). Facilitating success for students from low socioeconomic status backgrounds at regional universities. Federation University Australia. https://www.ncsehe.edu.au/project/facilitating-success-students-lowsocioeconomic-status-backgrounds-regional-universities-2/

Dodd, E., Ellis, S., \& Singh, S. (2020). Making the invisible, visible: an innovative $21^{\text {st }}$ century approach to tertiary preparation, attainment and access for student equity. International Journal of Inclusive Education. https://doi.org/10.1080/13603116.2020.1831629

Drane, C., Vernon, L., \& O'Shea, S. (2020). The impact of 'learning at home' on the education outcomes of vulnerable children in Australia during the COVID-19 pandemic. National Centre for Student Equity in Higher Education. https://www.ncsehe.edu.au/publications/learning-at-home-educational-outcomes-vulnerable-children-australia-covid-19/

Engstrom, C., \& Tinto, V. (2008). Access without support is not opportunity. Change: The Magazine of Higher Learning, 40(1), 46-50. http://dx.doi.org/10.3200/CHNG.40.1.46-50

Fischer, S., Barnes, R. K., \& Kilpatrick, S. (2019). Equipping parents to support their children's higher education aspirations: A design and evaluation tool. Educational Review, 71(2), 198-217. http://dx.doi.org/10.1080/00131911.2017.1379472

Halsey, J. (2018). Independent Review into Regional, Rural and Remote Education: Final Report. Australian Government Department of Education. https://apo.org.au/sites/default/files/resource-files/2018-04/apo-nid141326.pdf 
Hodges, C., Moore, S., Lockee, B., Trust, T., \& Bond, A. (2020). The difference between emergency remote teaching and online learning. Educause Review. https://er.educause.edu/articles/2020/3/the-difference-between-emergency-remoteteaching-and-online-learning

Irwin, E., Baker, S., \& Carter, B. (2018). What 'counts' as numeracy preparation in enabling education programs? Results of a national audit. Journal of Academic Language \& Learning, 12(1), 141-155. https://journal.aall.org.au/index.php/jall/index

Knightley, W. M. (2007). Adult learners online: Students' experiences of learning online. Australian Journal of Adult Learning, 47(2), 264-287. https://ajal.net.au/

Koshy, P. (2018). Equity student participation in Australian higher education: 2012 to 2017. National Centre for Student Equity in Higher Education. https://www.ncsehe.edu.au/publications/equity-student-participation-australian-highereducation-2012-2016/

Lamb, S., Maire, Q., Doecke, E., Noble, K., Pilcher, S., \& Macklin S. (2020). Impact of learning from home on educational outcomes for disadvantaged children. Mitchell Institute. https:/www.vu.edu.au/mitchell-institute/schooling/impact-oflearning-from-home-for-disadvantaged-children

Lawrence, J. (2004). University journeys: Alternative entry students and their construction of a means of succeeding in an unfamiliar university culture [Doctoral dissertation]. University of Southern Queensland.

Li, I.W., \& Dockery, M. (2015). Socio-economic status of schools and university academics performance: Implications for Australia's higher education expansion. National Centre for Student Equity in Higher Education. https://www.ncsehe.edu.au/publications/socio-economic-status-of-schools-university-academic-performance/

Lenzen, M., Li, M., Malik, A., Pomponi, F., Sun, Y., Wiedmann, T., Faturay, F., Fry, J., Gallego, B., Geschke, A., GómezParedes, J., Kanemoto, K., Kenway, S., Nansai, K., Prokopenko, M., Wakiyama, T., Wang, Y., \& Yousefzadeh, M. (2020). Global socio-economic losses and environmental gains from the Coronavirus pandemic. PLoS One, 15(7), 1-13. http://dx.doi.org/10.1371/journal.pone.0235654

Masters, G. N., Taylor-Guy, P., Fraillon, J., \& Chase, A.-M. (2020). Ministerial briefing paper on evidence of the likely impact on educational outcomes of vulnerable children learning at home during COVID-19. Australian Government Department of Education, Skills and Employment. https://research.acer.edu.au/learning_processes/24/

McLachlan, R., Gilfillan, G., \& Gordon, J. (2013). Deep and persistent disadvantage in Australia, rev. Australian Government Productivity Commission.

Naylor, R., \& Mifsud, R. (2019). Structural inequality in higher education: Creating institutional cultures that enable all students. National Centre for Student Equity in Higher Education. https://www.ncsehe.edu.au/publications/structuralinequality-retention-equity-students/

O'Sullivan, K., Bird, N., Robson, J., \& Winters, N. (2019). Academic identity, confidence and belonging: The role of contextualised admissions and foundation years in higher education. British Educational Research Journal, 45(3), 554575. https://doi.org/10.1002/berj.3513

OECD. (2018). Equity in education: Breaking down barriers to social mobility. OECD Publishing. https://doi.org/10.1787/9789264073234-en

Penman, J. (2010). Creating stronger ties and engagements with secondary and primary schools: A way forward for regional universities. Studies in Learning Evaluation, 7(2), 28-41.

Rainford, J. (2020). Moving widening participation outreach online: Challenge or opportunity? Perspectives: Policy and Practice in Higher Education, 1-5. http://dx.doi.org/10.1080/13603108.2020.1785968

Rapid Research Information Forum. (2020). Differential learning outcomes for online versus in-class education. Office of the Chief Scientist (Australia). https://apo.org.au/node/303772

Schwartz, S. (2004). Fair admission to higher education: Recommendations for good practice. Department for Education and Skills Publications. https://www.voced.edu.au/content/ngv\%3A12058

Shergold, P., Calma, T., Russo, S., Walton, P., Westacott, J., Zoellner, D., \& O’Reilly, P. (2020). Looking to the future: Report of the review of senior secondary pathways into work, further education and training. Education Council. https://www.dese.gov.au/quality-schools-package/resources/review-senior-secondary-pathways

Simson, L., Kelly, T., Moore, I., Pittard, S., Mendis, S., Lukomskyj, N., \& Woolnough, J. (2012). An alternative pathway for tertiary science education: Managing student access, diversity and inclusion in tertiary level science. International Journal of Innovation in Science and Mathematics Education, 20, 42-53. https://openjournals.library.sydney.edu.au/index.php/CAL/index

Slack, K., Mangan, J., Hughes, A., \& Davies, P. (2014). 'Hot', 'cold' and 'warm' information and higher education decision making. British Journal of Sociology of Education, 35(2): 204-223. https://doi.org/10.1080/01425692.2012.741803

Stone, C. (2017). Opportunity through online learning: Improving student access, participation and success in higher education. National Centre for Student Equity in Higher Education https://www.ncsehe.edu.au/publications/opportunityonline-learning-improving-student-access-participation-success-higher-education/ 
The Smith Family. (2020). COVID-19 insights snapshot: The challenges of surviving COVID-19 in Australia's hardest hit communities. https://www.thesmithfamily.com.au/about-us/media/2020/the-challenges-of-surviving-covid-19-insightsfrom-australias-hardest-hit-communities

Vagelos, O. (2020). Online learning: Designing for engagement and collaboration. IDEO U Blog.

https://www.ideou.com/blogs/inspiration/online-learning-designing-for-engagement-and-collaboration

Yin, R.K. (1984). Case study research: Design and methods. Sage Publications: California.

\section{Please cite this article as:}

Dodd, E., Singh, S., Micsko, J., Austin, K., Morison, C., \& Upton, S. (2021). Equalizing and widening access to higher education during a pandemic: Lessons learned from a multi-university perspective. Student Success, 12(3), 58-72. https://doi.org/10.5204/ssj.1715

This article has been peer reviewed and accepted for publication in Student Success. Please see the Editorial Policies under the 'About' section of the Journal website for further information.

Student Success: A journal exploring the experiences of students in tertiary education.

(c) (i) Except where otherwise noted, content in this journal is licensed under a Creative Commons Attribution 4.0 International Licence. As an open access journal, articles are free to use with proper attribution. ISSN: 2205-0795 